\title{
Rooftop rainwater harvesting potential for a domestic purpose using samsamwater, case of Jimma University Institute of Technology, Ethiopia
}

Dessalegn Geleta Ebsa ( $\sim$ dessgeleta@gmail.com )

JIMMA UNIVERSITY INSTITUTE OF TECHNOLOGY https://orcid.org/0000-0001-5972-5768

Research Article

Keywords: Domestic, potential, rooftop, rainwater harvesting, SamSamwater

Posted Date: August 2nd, 2021

DOI: https://doi.org/10.21203/rs.3.rs-770252/v1

License: @ (i) This work is licensed under a Creative Commons Attribution 4.0 International License. Read Full License 


\begin{abstract}
The key sources of water supply are rainwater, underground water and surface water. Rooftop rainwater harvesting is a technique through which the rain is captured from the roof catchments. The objective of this study was to investigate rooftop rainwater harvesting potential for domestic purposes using a samsamwater tool. This can be used in dry and wet seasonal situations based on the roof size and population density, which plays a crucial role in socioeconomic development and keeping community school welfare. Rooftop rainwater harvesting is the most reliable, easiest to access, and suitable source for water supply. This study was carried out from June 2018 to December 2019 based on a case study of three Jimma University Institute of Technology Kito furdisa campus. Since then, rainfall data, rooftop catchment, water consumption and water demand data have been used as inputs.
\end{abstract}

Based on the findings, the annual rainfall is $1846 \mathrm{~mm}$. The total roof size of the school is $888.32 \mathrm{~m}^{2}$ and almost the entire age of the building ranges between 5-15 years. It has been constructed of galvanized iron in which its run off coefficient is estimated at $90 \%$. The collected data has been analyzed using different tools, including the Samsamwater RWH model, and SPSS statistics version 22 . As a result, the volume of harvested rainwater was $12,826 \mathrm{~m}^{3} / \mathrm{yr}$, which covered all non-potable water needs for 14,458 of the school population. The total yearly water requirement for a working day (182 days) and working days plus no working days (365 days) of the school is $18,606.72$ and $26,759.47 \mathrm{~m}^{3} / \mathrm{yr}$. respectively. The reliability of harvested rainwater from the rooftop for the community school can meet about $63.4 \%$ of the water scarcity reduced by feeding for (365days). Whereas the reliability of rainwater-harvested potential is, $82 \%$ of water demand can be met by considering the schedule of working days ( 9 months). The average reliable for the study area is greater than $72.6 \%$ of water demand.

\title{
1. Introduction
}

Water is a basic human requirement, which may be sourced from surface water, groundwater, or rainwater (Dagnachew A., 2018; Dou, 2016). Today, sources say this is becoming diminished due to the population rise, climate change, and pollution, which are causing global water scarcity, especially in developing countries (Seyoum, 2017). According to a study estimate reported by (Yemenu, 2017; Development, 2006), more than 2000 million people will live under the condition of high-water stress by the year 2050 , which is one of the main factors that can affect the socio-economic development of any country. The quality of life depends on the adequate supply of fresh water, which can be influenced by population dynamics, which has imposed heavy pressure on fresh water resources through increased water demand and pollution (Dagnachew A., 2018; Todini, 2017). Rooftop rainwater harvesting is the most economical and easiest technical method of conserving water. This paper deals with the rooftop rainwater harvesting potential in Agaro town community school by using the Samsam rainwater-harvesting tool. The shortage of water has become a serious problem around the world and is assumed to be related to the increase in the population, rapid urbanization, and climatic changes (Prasad, 2014; Todini, 2015).

Jimma University Institute of Technology's Kito Furdisa University is among the most highly populated in the university and changes had to be made area. This ended up causing overpopulation and tends to increase water demand, doubling water consumption rates. Thus, roof top rainwater harvesting is one solution for reducing water shortages for both surface and groundwater sources.

\section{Materials And Methods}

\subsection{Description of the study area}

The study was conducted in Oromia Regional State, of Jimma zone in Jimma University Institute of technology Kito furdisa campus. Geographically this area is located between $7^{\circ} 51^{\prime} \mathrm{N}$ and $36^{\circ} 35^{\prime} \mathrm{E}$ which is $346 \mathrm{~km}$ far away from Addis Ababa city.

\subsection{Population Study}

The main objective of any water supply distribution is to provide safe and adequate potable water to the beneficiaries. The main user of the rooftop rainwater harvesting is the whole community school, which is found in the Jimma University Institute of Technology (JIT) campus in a three-student dorm block. The forecasted community population is listed in below Table 1, is the number of students and staff members respectively.

Table 1

study population observed for Jimma zone in Jimma University Institute of technology Kito furdisa campus

\begin{tabular}{|llccc|}
\hline No & Name of student Dorm & Men & Female & Sum \\
\hline 1 & Block 3 & & 9226 & \\
2 & Block 4 & 2730 & & \\
3 & Block 5 & 1464 & & \\
\hline 4 & Total community school populations & 14,458 \\
\hline
\end{tabular}

\subsection{Determination of Roof Catchment Area}

The roof catchment rainwater harvesting system consists of the rooftop that provides the catchment area that should be measured in the field directly. This was obtained by the mathematical language of multiplying the length $(\mathrm{m})$ by the width $(\mathrm{m})$, if the roof is rectangular, but it depends on the shape of the catchment. Therefore, for each section of the classroom, since its shape is rectangular, it can be determined using the (Area of the roof catchment $(A)=$ width * 
length). For each community school, the summation of the roof catchment area for harvesting rainwater to meet the rising water demand for each community school is listed in below Table 2.

Table 2

Estimation of school rooftop catchment area

\begin{tabular}{|ll|}
\hline JIT Kito furdisa campus estimation of rooftop catchment for three student dorms estimation of rooftop catchment area \\
\hline Name of Dorms & Average Roof Area $\left(\mathrm{m}^{2}\right)$ \\
\hline Block 3 & 524.32 \\
\hline Block 4 & 223.32 \\
\hline Block 5 & 241.5 \\
\hline
\end{tabular}

\subsection{Average age of rooftop}

The roof catchment area is just where rainwater is harvested from rooftops; however, the age of the roof material has an impact on both the quantity and quality of rainwater-harvested potential. The primary factor affecting the quality and quantity of rainwater harvesting potential is indeed the age of the roof material. When it is very old, it requires more time for first flushing, which can be used for non-potable purposes. It has been identified that the type of roof material for the school roof is galvanized iron with a medium age of 5-15 years old. The age of buildings has been described in five-year intervals for simplification of estimation of the age of roof materials.

\subsection{Average water consumption rates for JIT Kito furdisa campus student dorms}

The water source for JIT (Kito Furdisa campus) was identified as a ground water source, which was not enough to distribute to the community school. The average water consumption rates of (students, staff members, and others who stay in higher education, colleges, and secondary or primary schools vary based on the time of delay. Thus, the average water consumption rate for the school community can be classified into board schools and school days is 5 $\mathrm{L} /$ pupil per day school and $60 \mathrm{~L} /$ pupil for board school or campus services.

\subsection{Estimation of water demand for community school}

The water demand was varying for wet and dry seasons, for instance during wet season, there were high excessive rain water harvested and less consumption rates that has be stored for some dry months. This can be based on the number of hours to be stayed at school for instance the excluding the weekends there were 22 working days in each month. Among this day, the students were stayed maximum for 24 hrs per days.

Table 3

Estimation of water demand for community school

\begin{tabular}{|c|c|c|c|c|c|c|}
\hline Month & $\begin{array}{l}\text { Working } \\
\text { (days) }\end{array}$ & $\begin{array}{l}\text { weekends } \\
\& \\
\text { non- } \\
\text { working }\end{array}$ & $\begin{array}{l}\text { Average water } \\
\text { consumption(Lpd) }\end{array}$ & $\begin{array}{l}\text { Population } \\
\text { No }\end{array}$ & $\begin{array}{l}\text { monthly water demand } \\
\text { ( } \mathrm{m}^{3} / \text { month) }\end{array}$ & $\begin{array}{l}\text { Annual water demand } \\
\left(\mathrm{m}^{3} / \text { year) }\right.\end{array}$ \\
\hline Jan & 14 & 16 & \multirow[t]{12}{*}{5} & \multirow[t]{12}{*}{14,458} & 942.06 & \multirow[t]{12}{*}{$18,370.17$} \\
\hline Feb & 19 & 11 & & & 1278.5 & \\
\hline Mar & 22 & 8 & & & 1490.4 & \\
\hline Apr & 21 & 9 & & & 1413.1 & \\
\hline May & 20 & 10 & & & 1345.8 & \\
\hline Jun & 16 & 14 & & & 1076.6 & \\
\hline Jul & & 30 & & & 0 & \\
\hline Aug & & 30 & & & 0 & \\
\hline Sept & 22 & 8 & & & 1480.4 & \\
\hline Oct & 18 & 12 & & & 1211.2 & \\
\hline Nov & 12 & 18 & & & 807.5 & \\
\hline Dec & 18 & 12 & & & 1211.2 & \\
\hline Annual & 30 days & & 20 & $\begin{array}{l}389 \text { for } \\
\text { staff }\end{array}$ & 42.75 & 236.55 \\
\hline Total & 182 & 178 & & & $12,299.51$ & $18,606.72$ \\
\hline
\end{tabular}

\section{Results And Discussion}

3.1. Rainwater Harvesting potential results for JIT Kito furdisa campus, student dorm block three (3) 
The optimum size for a storage reservoir for this rainwater harvesting system is $369,700 \mathrm{~L}\left(369.7 \mathrm{~m}^{3}\right)$ and the details of the results and calculations were found in below Table 4.

3.2. Rainfall for JIT Kito furdisa campus, student dorm block three (3) Jimma, Ethiopia

The annual rainfall for this area can vary between $33.1 \mathrm{~mm}$ in the driest month (December) and $289.6 \mathrm{~mm}$ in the wettest month (July). In general, the total annual rainfall for this area is $1846 \mathrm{~mm}$.

3.1.2. Water availability for JIT Kito furdisa campus, student dorm block 3

The type of roof top material is a galvanized iron, which has a runoff coefficient of 0.9 , which means that $90 \%$ of the rain can be harvested. Based on this runoff coefficient and the roof catchment areas of the schools were 885.36 square meters and the volume of $26,375 \mathrm{~L}\left(33.1 \mathrm{~mm} \times 885.36 \mathrm{~m}^{2} \times 0.9\right)$ of water can be collected in the driest month (December) and $230760 \mathrm{~L}\left(289.6 \mathrm{~mm} \times 30 \mathrm{~m}^{2} \times 0.9\right)$ in the wettest month (July). The total yearly amount of water that can be collected from the roof is $1,471,200 \mathrm{~L}\left(1471 \mathrm{~m}^{3}\right)$ in an average year.

3.1.3. Water demand for JIT Kito furdisa campus, student dorm block 3

The daily water needs of Jidda secondary high school was $3945 \mathrm{~L}$ per day, which equals to about $118,350 \mathrm{~L}$ per month. Therefore, the average yearly water demand of the school was for about, 1439,900 L (1439.925 $\mathrm{m}^{3}$ ) per year. Thus, during five months of the year (May, June, July, August and September) the amount of water could be collected from the rooftop is larger than the water demand. The excess water should be stored to be used in the months when the water availability is smaller than the average demand.

The average annual water demand and monthly demand were described in the below Figure 3 for this community schools were plotted against the rooftop rainwater available.

3.1.5. The Required storage tank for JIT Kito furdisa campus, student dorm block 3

The storage tank that required for this school was constructed to collect and store the water during the wet months so this water was used during the dry months. For this location, roof size and water demand the optimum size of a storage tank is $369,700 \mathrm{~L}\left(369.7 \mathrm{~m}^{3}\right)$. The storage reservoir will be full in and then slowly drain until it is (almost) empty at the end of April.

\subsubsection{Dry and wet Months}

The dry and wet situation of the annual calculation was based on the average monthly rainfall. The actual rainfall differs from month to month and year to year. The amount of available water and the filling of the tank might therefore be different and change from year to year. When constructing a rainwater harvesting system, it is important to consider this description of the situation in a dry year ( $20 \%$ chance) and a wet year ( $20 \%$ chance). Situation in a dry year: there is no need to take additional measures. Situation in a wet year: there would be more than enough water. There is no need to take additional measures.

\subsection{Rainwater harvesting potential for JIT Kito furdisa campus, student dorm block 4}

The total amount of water that was collected from this roof is not enough to meet the total water demand. However, it might still be worthwhile to construct a rainwater harvesting system. With a storage reservoir of $404,900 \mathrm{~L}\left(404.9 \mathrm{~m}^{3}\right)$, a rainwater harvesting system could provide $4208 \mathrm{~L}$ of water per day, which is $52 \%$ of the total demand, and the details of the results and calculations are described in below Table 5 .

\subsubsection{Rainfall for JIT Kito furdisa campus, student dorm block 4}

The average rainfall at this location varies between $33.1 \mathrm{~mm}$ in the driest month (December) and $289.6 \mathrm{~mm}$ in the wettest month (July) and the total annual rainfall is $1846 \mathrm{~mm}$ as below Figure 5 .

\subsubsection{Water availability JIT Kito furdisa campus, student dorm block 4}

The steel roof has a runoff coefficient of 0.9 , which means that $90 \%$ of the rain was harvested. Based on this runoff coefficient and a roof area of 924.32 square meters, a volume of $27,535 \mathrm{~L}\left(33.1 \mathrm{~mm} \times 924.32 \mathrm{~m}^{2} \times 0.9\right)$ of water can be collected in the driest month (December) and $240915 \mathrm{~L}\left(289.6 \mathrm{~mm} \times 30 \mathrm{~m}{ }^{2}\right.$ $x$ 0.9) in the wettest month (July). The total yearly amount of water that is collected from the rooftop is $1,535,900 \mathrm{~L}\left(1536 \mathrm{~m}^{3}\right)$ in an average year.

\subsubsection{Water demand for JIT Kito furdisa campus, student dorm block 4}

The water demand of the school is $8,135 \mathrm{~L}$ per day, which equals about $244,050 \mathrm{~L}$ per month. The total water demand is $2,969,300 \mathrm{~L}\left(2,969.275 \mathrm{~m}^{3}\right)$ per year. The amount of water that might be collected from the roof $\left(1536 \mathrm{~m}^{3}\right)$ is less than the water demand $\left(2969.275 \mathrm{~m}^{3}\right)$. Only a part of the water demand was fulfilled using a rainwater harvesting system.

\subsubsection{The required storage tank for JIT Kito furdisa campus, student dorm block 4}

The total amount of water that was collected from this rooftop, 1,535,900 L, is not enough to fulfil the total annual water demand of 2,969,300 L. However, it might still be worthwhile to construct a rainwater harvesting system. With a storage reservoir of 404,900 L (404.9 $\left.\mathrm{m}^{3}\right)$, a rainwater harvesting system could 
provide $4208 \mathrm{~L}$ of water per day, which is $52 \%$ of the total demand. The storage reservoir will be full in and then slowly drain until it is (almost) empty at the end of April.

\subsubsection{Dry and wet Months}

This calculation was based on the average monthly rainfall. The actual rainfall varied from month to month and from year to year. The amount of available water and the filling of the tank might therefore be different and change from year to year. When constructing a rainwater harvesting system, it is important to consider this. Below is a description of the situation in a dry year ( $20 \%$ chance) and a wet year ( $20 \%$ chance). Situation in a dry year: during a dry year, there is less rain to fill the system. The system should provide a smaller amount of water compared to an average year. All the rain is stored, so constructing a larger reservoir did not help. Situation in a wet year: During a wet year, there is more water available and constructing a larger tank will increase the water availability in this situation. With a storage reservoir of $463,700 \mathrm{~L}\left(463.7 \mathrm{~m}^{3}\right)$, a rainwater harvesting system could provide $68 \%$ of the total demand.

3.3. Rainfall data for JIT Kito furdisa campus, student dorm block 5

The average rainfall at this location varies between $33.1 \mathrm{~mm}$ in the driest month (December) and $289.6 \mathrm{~mm}$ in the wettest month (July). The total annual rainfall in an average year is $1846 \mathrm{~mm}$.

\subsubsection{Water availability for JIT Kito furdisa campus, student dorm block 5}

A metal roof has a runoff coefficient of 0.9 , which means that $90 \%$ of the rains were harvested. Based on this runoff coefficient and a roof area of 523.32 squa of 15,590 litres $\left(33.1 \mathrm{~mm} \times 523.32 \mathrm{~m}^{2} \times 0.9\right)$ of water can be collected in the driest month

(December) and 136,398 litres (289.6 mm x $\left.30 \mathrm{~m}^{2} \times 0.9\right)$ in the wettest month (July). The total yearly amount of water that were collected from the roof is 869,600 litres $\left(870 \mathrm{~m}^{3}\right)$ in an average year.

\subsubsection{Water demand for JIT Kito furdisa campus, student dorm block 5}

The water demand is 20,000 litres per day, which equals to about 600,000 litres per month. The total water demand is 7300,000 litres $\left(7300 \mathrm{~m}^{3}\right)$ per year. The amount of water that had been collected from the roof $\left(870 \mathrm{~m}^{3}\right)$ is less than the water demand $\left(7300 \mathrm{~m}^{3}\right)$. Only a part of the water demand was fulfilled using a rainwater harvesting system.

As shown in the below figure 10 RTRWH potential for Jidda first primary school did not meeting to the average and monthly water demand, so it needs to search other water source

3.3.5. The required storage tank for JIT Kito furdisa campus, student dorm block 5

The total amount of water that had be collected from this roof, $869,600 \mathrm{~L}$, is not enough to fulfil the total yearly water demand of $7300,000 \mathrm{~L}$. However, it might still be worthwhile to construct a rainwater harvesting system. With a storage reservoir of 229,300 L ( $\left.229.3 \mathrm{~m}^{3}\right)$, a rainwater harvesting system could provide $2382 \mathrm{~L}$ of water per day, which is $12 \%$ of the total demand. The storage reservoir will be full in and then slowly drain until it is (almost) empty at the end of April.

\subsubsection{Dry and wet months}

This calculation was based on the average monthly rainfall. The actual rainfall differs from month to month and year to year. The amount of available water and filling of the tank might therefore be different and change from year to year. When constructing a rainwater harvesting system it is important to consider this, a description of the situation in a dry year ( $20 \%$ chance) and a wet year ( $20 \%$ chance).

Situation in a dry year: during a dry year, there is less rain to fill the system. The system can provide a smaller amount of water compared to an average year. All rain is stored, so constructing a larger reservoir did not help.

Situation in a wet year: During a wet year, there is more water available and constructing a larger tank will increase the water availability in this situation. With a storage reservoir of $262500 \mathrm{~L}\left(262.5 \mathrm{~m}^{3}\right)$, a rainwater harvesting system could provide $16 \%$ of the total demand.

\section{Conclusion}

The rooftop rainwater harvesting plays a great role in the socio-economic development of the country for modeling the health status of the society. However, this was influenced by roof sizing, community density, escape coefficient and patterns of rainfall, especially the patterns of rainfall for the study area were varying for seasonal situation. the amount of annual precipitation is rise to $1846 \mathrm{~mm}$, which is almost enough to fulfill demand of the school by ( $63.4 \%$ and $82 \%$ ) from RTRWH, without searching any other water source. depending on the above results, the accessibility of water supply for this study area is achieving to $63.4 \%$ had meeting to the water needs from the roof harvesting in averagely. the amount of harvested rainwater is $12,826 \mathrm{~m}^{3} / \mathrm{y}$ from the whole roof catchments of $2480.84 \mathrm{~m} 2$ with the roof material run off coefficient $90 \%$. Whereas the yearly water requirements to the JIT Kito furdisa campus is for about $26,759.47 \mathrm{~m}^{3} / \mathrm{y}$, which is overburden for the source of water. The volume of harvested water from each school was satisfy the school demands up to $82 \%$. This contributes to reducing the scarcity of water needs for the JIT Kito furdisa campus, by providing as an alternative solution for increased water demand. 


\section{Declarations}

\section{ACKNOWLEDGEMENTS}

First, I might wish to thank Almighty God for providing me with healthiness, wisdom and strength throughout my duty and help me to complete this study. I would like to thank, JIT instructors those gave the feedback and comments on this research. I favor to thank Jimma University Institute of a technology, which sponsored funds for this research and supporting certain field survey activities

\section{References}

Dagnachew, S., 2018. Assessing the Potential for Rooftop Rainwater Harvesting from Large Public Institutions. International Journal of Environmental Research and Public Health, 6(2), pp. 123-129.

Development, M., 2006. Ethiopia: Sustainable development and poverty reduction program, Addis Ababa,: Ethiopia.

Dou, M., 2016. Steady state groundwater flow. flow, 37(11), pp. 2709-2719.

Fitsume Yemenu, A., 2017. Review of Water Harvesting Technologies for Food Security in Ethiopia..

Hashim, H., 2015. Simulation based programming for optimization of large-scale rainwater harvesting system: Malaysia case study. Resour. Conserv. Recycl., 80(2), pp. 1-9.

Kimeu, N. a., 2014. Rainwater harvesting one solution to the problems of water shortage, s.l.: Africa.

Panigrahi, S., 2017. Rooftop rainwater harvesting system for official. Int. Journal of Engineering Research and Application www.ijera.com, 7(1), pp. 111-115. Prasad, N., 2014. Multiobjective genetic algorithms for design of water distribution networks,. Journal of water resources planning and management, 130(1), pp. 73-82.

Seyoum, M., 2017. Overview of Ethiopia Rainwater Harvesting Association. In 'Integrated water and land management research and capacity building priorities for Ethiopia'. 7(3).

Thomas, D., 2015. Roof water Harvesting: A Handbook for Practitioners. International Water and Sanitation Centre, Volume 49 , p. 160.

Todini, E., 2015. Looped water distribution networks design using a resilience index based heuristic approach,Urban Water. 2(3), p. 115-122.

Todini, E., 2017. A gradient method for the analysis of pipe networks International Conference on Computer Application for Water Supply and Distribution.

Leicester Polytechnic, U.K..

Worm, J., 2015. Rainwater harvesting for domestic use, Agrodok43, Agromisa Foundation and CTA., Netherland: Wageningen.

Zhuang Booyu, Z., 2017. Vulnerability Assessment of Regional Water Distribution Systems. International Conference on Environmental Sciences and Information Application Technology, pp. $473-477$.

\section{Tables 4 And 5}

Table 4: Location, Roof material type and water consumption rates for Jidda secondary high schools.

Location: JIT Kito furdisa campus, student dorm block 3 Jimma, Ethiopia

Latitude Longitude Roof Size Roof Type Runoff coeff Water demand

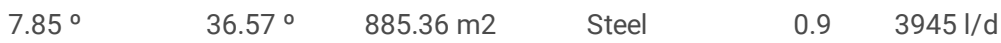

Table 5: Location, roof material type and characteristics of water consumption rates for student dorm block 4

Location: JIT Kito furdisa campus, student dorm block 4 Jimma town, Ethiopia

Latitude Longitude Roof Size Roof Type Runoff coeff Water demand

$\begin{array}{lllll}7.85^{\circ} & 36.57^{\circ} & 924.32 \mathrm{~m} 2 & \text { Metal } & 0.9\end{array}$

\section{Figures}




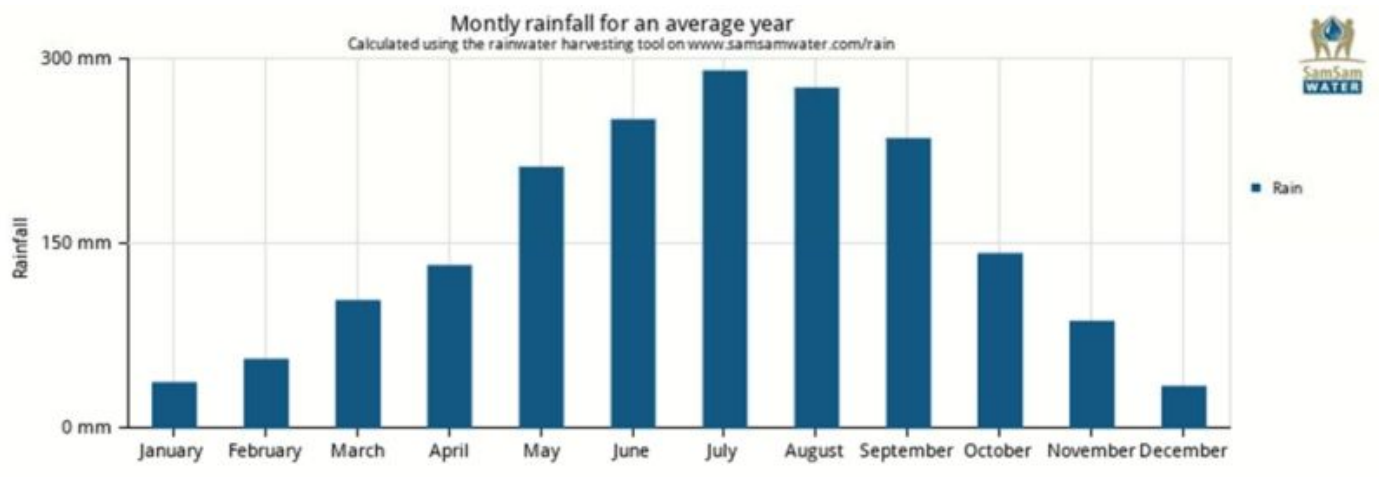

Figure 1

Average monthly rainfall for JIT Kito furdisa campus, student dorm block 3

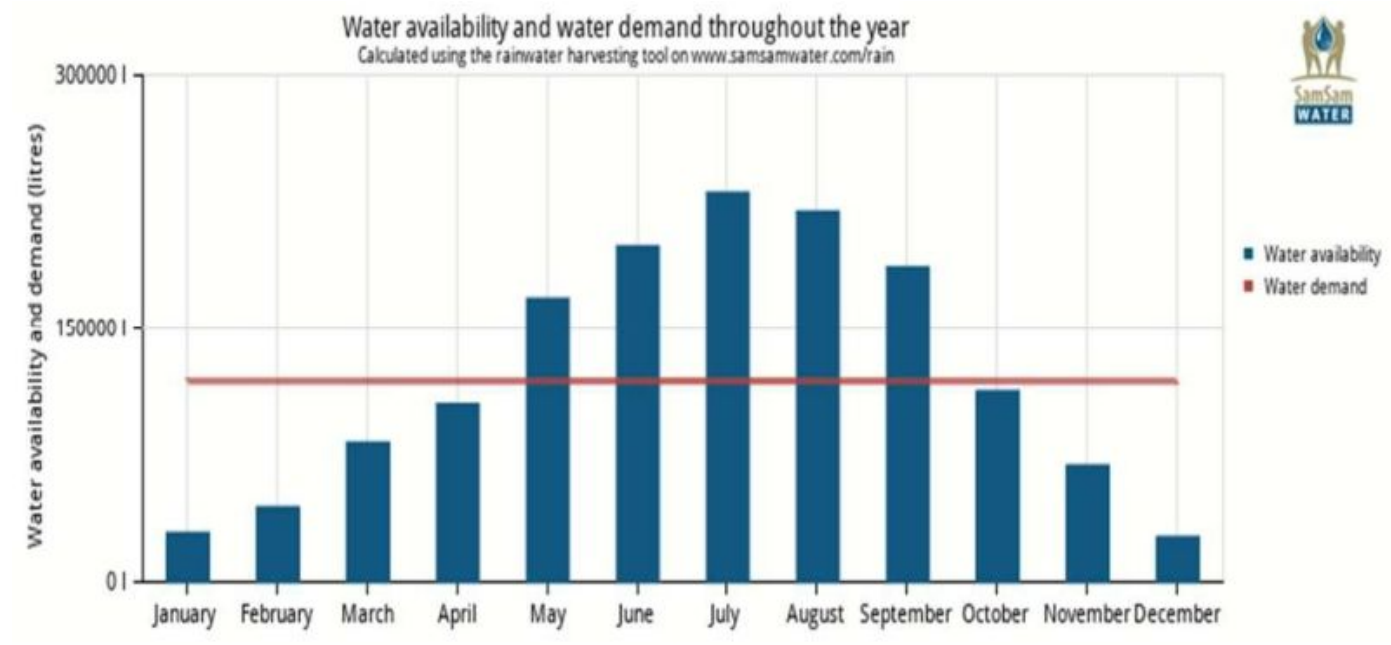

Figure 2

The annual availability of water and water demand for JIT Kito furdisa campus, student dorm block 3

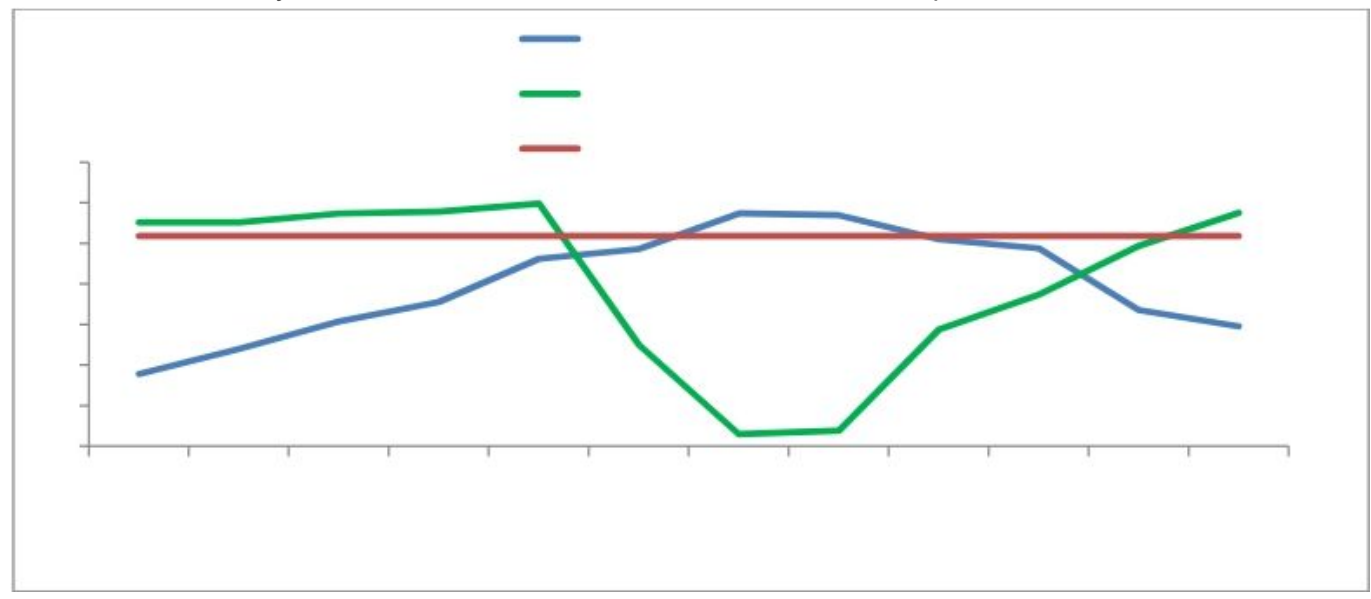

Figure 3

Average RTRWH availability, monthly and annual water demand for JIT Kito furdisa campus, student dorm block 3 


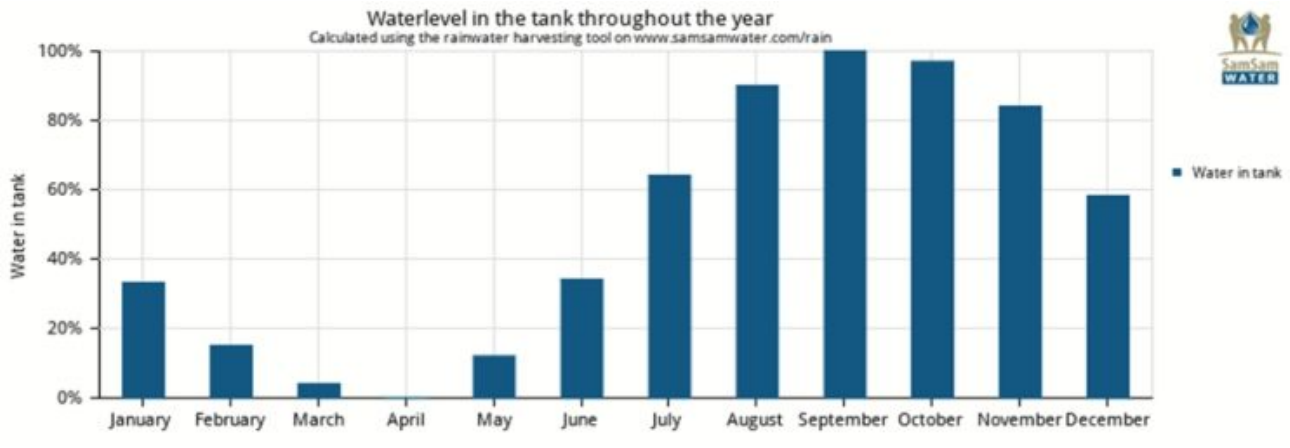

Figure 4

Storage tank required for JIT Kito furdisa campus, student dorm block 3

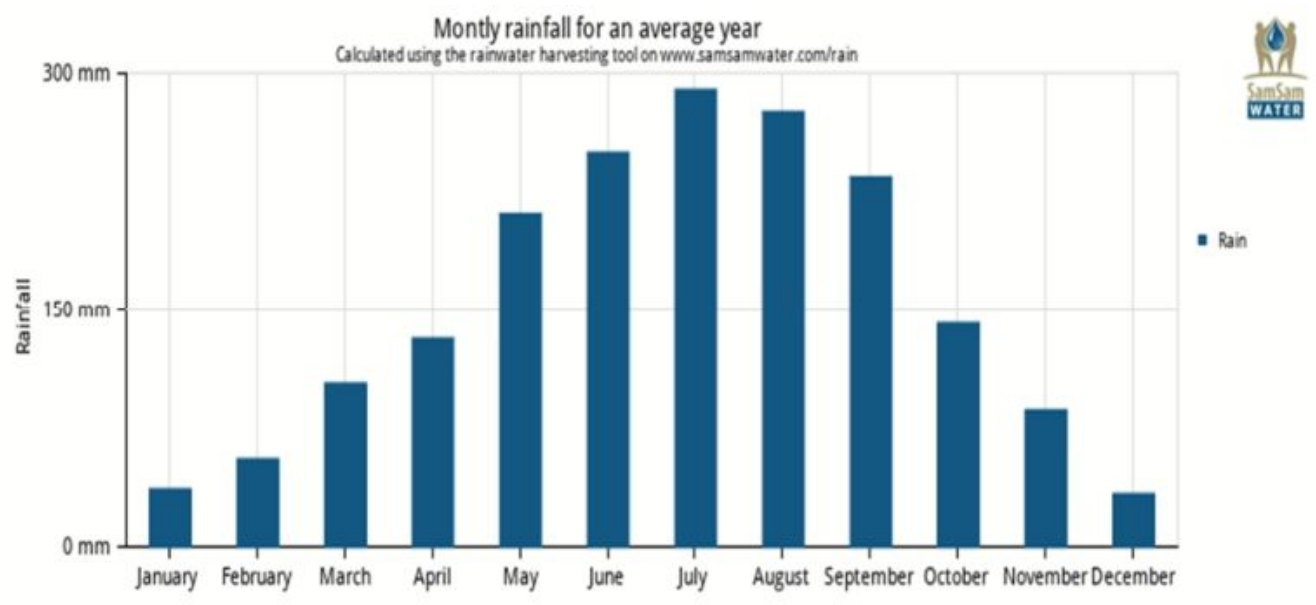

Figure 5

monthly rainfall for JIT Kito furdisa campus, student dorm block 4

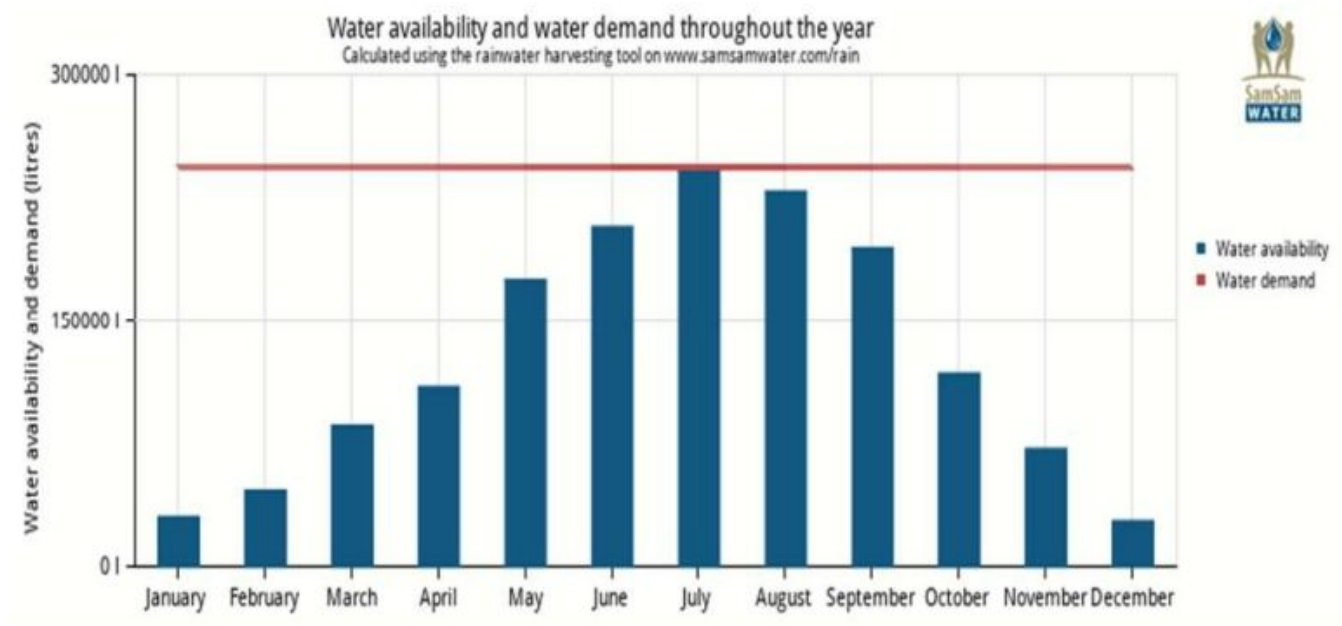

Figure 6

Water availability and water demand for JIT Kito furdisa campus, student dorm block 4 The average water demand and monthly demand was meeting to rooftop rainwater harvesting only in the summary season as indicates in Figure 7. 


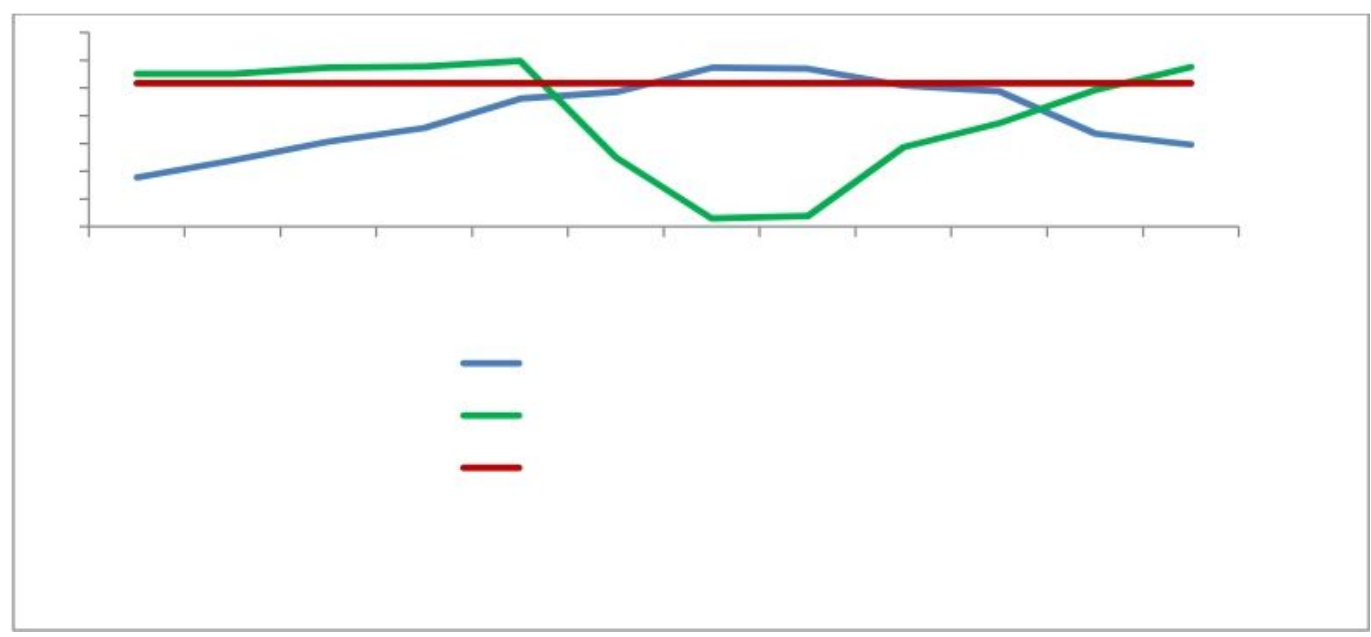

Figure 7

Aveg.RTRWH availability in $\mathrm{mm}$, and Monthly and average Annual water demand in meter cubic

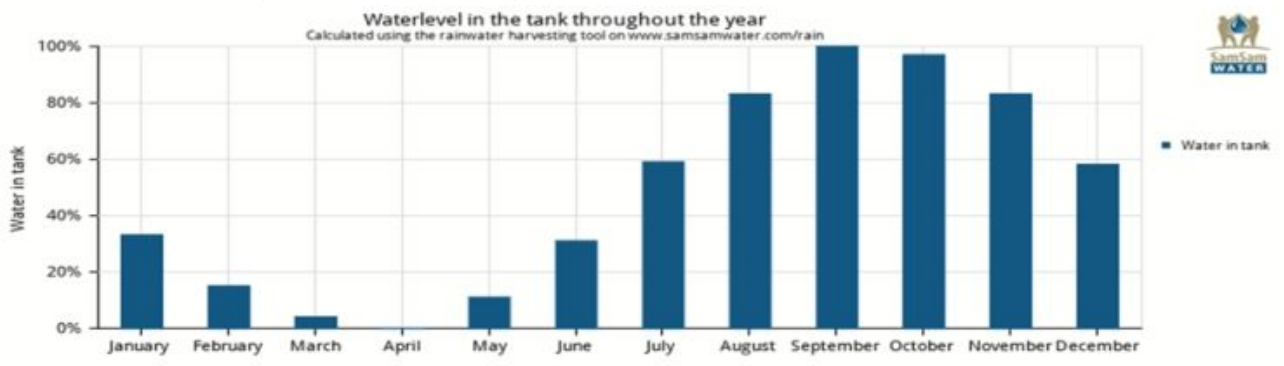

Figure 8

required storage tank for JIT Kito furdisa campus, student dorm block 4

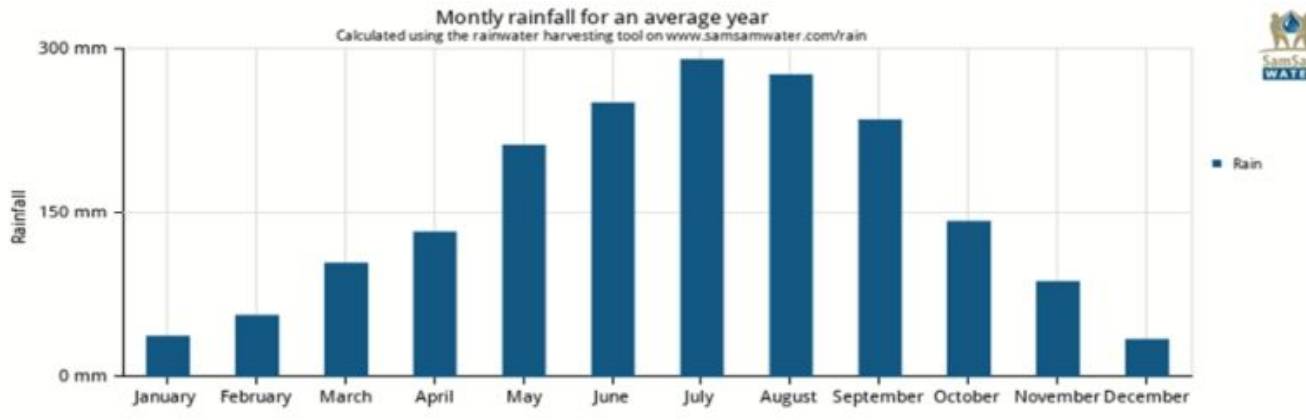

Figure 9

rainfall data for JIT Kito furdisa campus, student dorm block 5

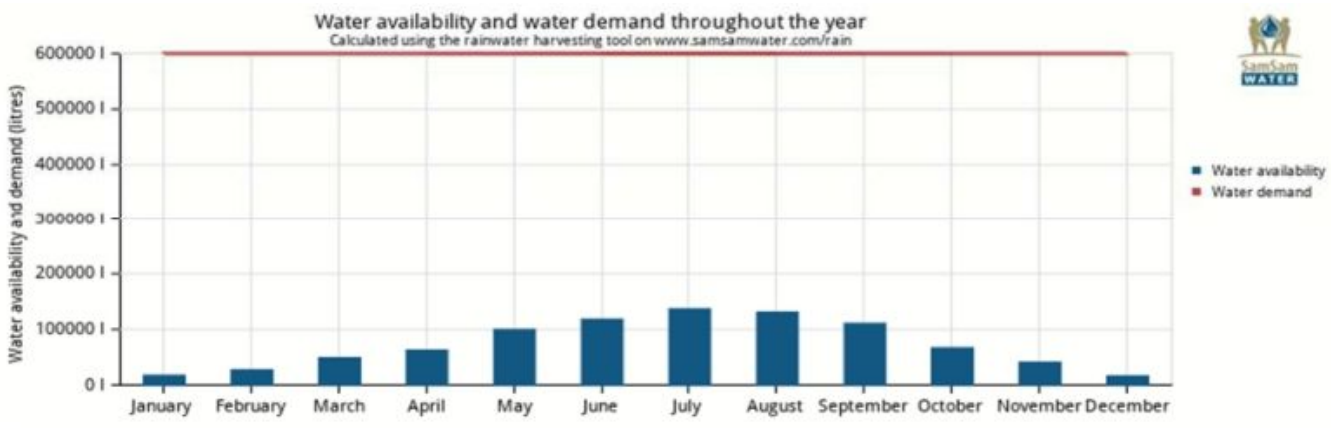

\section{Figure 10}

Annual water available and water demand JIT Kito furdisa campus, student dorm block 5 


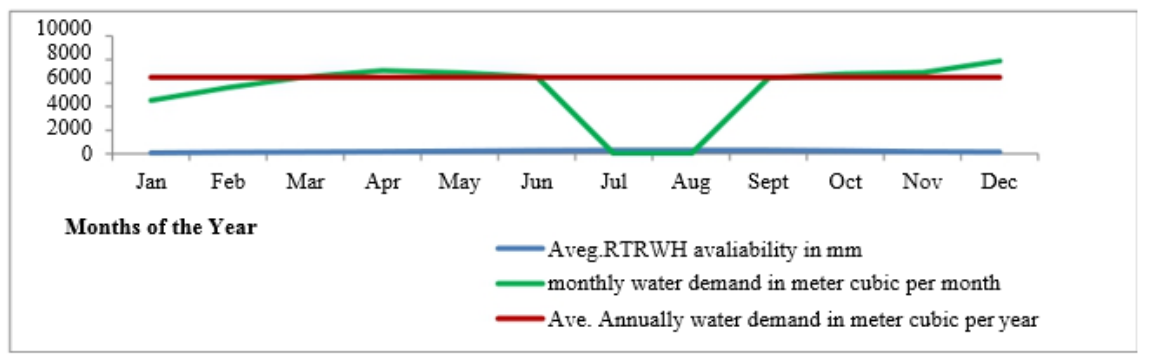

\section{Figure 11}

Aveg.RTRWH availability in mm, and Monthly and Average Annual water demand to JIT Kito furdisa campus, student dorm block 4

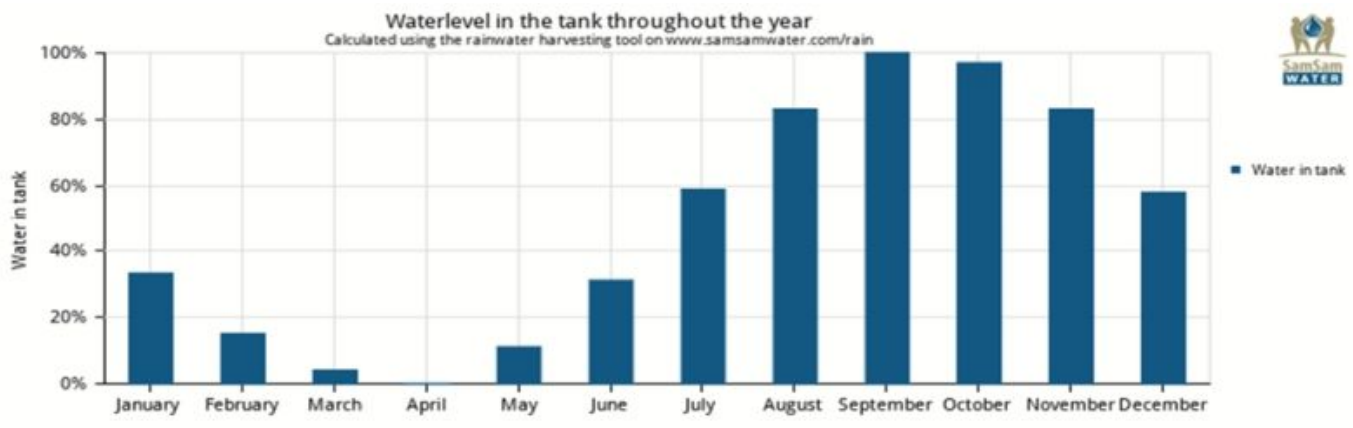

\section{Figure 12}

The storage tank level JIT Kito furdisa campus, student dorm block 5 3.3.5. Dry and wet months 